\title{
Author Correction: Amazonian forest-savanna bistability and human impact
}

\author{
Bert Wuyts, Alan R. Champneys \& Joanna I. House
}

Nature Communications 8:15519 doi:10.1038/ncomms15519 (2017); Published online 30 May 2017; Updated 21 Feb 2018

In the originally published version of this Article, reference 23 did not refer to the correct paper. This error has now been corrected in both the HTML and PDF versions of the Article.

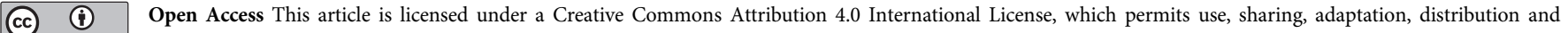
reproduction in any medium or format, as long as you give appropriate credit to the original author(s) and the source, provide a link to the Creative Commons license, and indicate if changes were made. The images or other third party material in this article are included in the article's Creative Commons license, unless indicated otherwise in

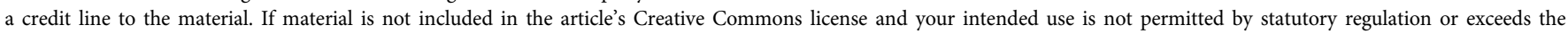
permitted use, you will need to obtain permission directly from the copyright holder. To view a copy of this license, visit http://creativecommons.org/licenses/by/4.0/

(C) The Author(s) 2018 